Check for updates

Cite this: RSC Adv., 2018, 8, 4584

Received 23rd November 2017 Accepted 20th January 2018

DOI: 10.1039/c7ra12716b

rsc.li/rsc-advances

\section{Catalyst- and solvent-free approach to 2-arylated quinolines via [5 + 1] annulation of 2- methylquinolines with diynones $\uparrow$}

\author{
Hai-Yuan Zhao, $t^{\mathrm{ab}}$ Fu-Song Wu, $\dot{t}^{\mathrm{b}}$ Li Yang, ${ }^{\mathrm{c}}$ Ying Liang, ${ }^{\text {*a }}$ Xiao-Lin Cao, \\ Heng-Shan Wang (DD ${ }^{b}$ and Ying-Ming Pan (DD *b
}

A novel route for the synthesis of 2-arylated quinolines through a $[5+1]$ annulation directly from 2methylquinolines and diynones under catalyst-free and solvent-free conditions was disclosed. This synthetic process was atom-economic, with good tolerance of a broad range of functional groups, and with great practical worth.
Nitrogen-containing heterocyclic compounds are ubiquitous in natural molecules and exhibit a wide array of biological activities. ${ }^{1}$ Among various $\mathrm{N}$-heterocycles, quinoline nuclei are privileged scaffolds that occupy an important role in many medicinally relevant compounds. ${ }^{2}$ 2-Arylated quinolines are found in many medicinal compounds including etoricoxib, ${ }^{3}$ rosuvastatin, ${ }^{4}$ and gleevec, ${ }^{5}$ as well as molecules designed for other purposes including $\mathrm{P}, \mathrm{N}$ ligands, such as QUINAP. ${ }^{6}$ Because of their unique biological activity and wide application, the functionalized 2-arylated quinoline elicited considerable synthetic interest, and a variety of synthetic routes have been established. ${ }^{7}$ In addition, some classical synthetic methods such as Kumada, ${ }^{8}$ Suzuki, ${ }^{9}$ Negishi, ${ }^{10}$ or Stille ${ }^{9 b}$ are usually used to efficiently prepare these compounds, but these methods require the preparation of cross-coupling reagents such as Grignard reagents, boronic acids, organozincs, and organostannanes in advance and these cross-coupling reagents are unstable or toxic or can't be isolated as solids. ${ }^{11}$ More recently, much research has been directed toward the synthesis of 2arylated quinolones and their derivatives via transition-metalcatalyzed $\mathrm{C}-\mathrm{H}$ arylation ${ }^{12}$ and many other methods also have been developed by transitional-metal-catalyzed cross-

${ }^{a}$ School of Life and Environmental Sciences, Guilin University of Electronic Technology, Guilin, 541004, China. E-mail: yingl@aliyun.com

${ }^{b}$ State Key Laboratory for Chemistry and Molecular Engineering of Medicinal Resources, School of Chemistry and Pharmaceutical Sciences of Guangxi Normal University, Guilin 541004, China. E-mail: panym@mailbox.gxnu.edu.cn; Fax: +86773-5803930

${ }^{1}$ Guangxi Key Laboratory of Special Non-wood Forest Cultivation and Utilization, Guangxi Zhuang Autonomous Region Forestry Research Institute, Nanning, 530002, China

$\dagger$ Electronic supplementary information (ESI) available: Experimental procedures, characterization data and spectra data. CCDC 1534893. For ESI and crystallographic data in CIF or other electronic format see DOI: $10.1039 / \mathrm{c} 7 \mathrm{ra} 12716 \mathrm{~b}$

$\ddagger$ These authors contributed equally to this work. couplings. ${ }^{13}$ These transition metals included $\mathrm{Co}, \mathrm{Cu}$ or $\mathrm{Pd}$. Moreover, 2-arylated quinolines synthesis via direct $\mathrm{C}-\mathrm{H}$ arylation of quinolones with various aryl bromides, arylboronic acid, or arylzinc reagents catalyzed by transition metal catalyst, such as $\mathrm{Rh}, \mathrm{Fe}$, or $\mathrm{Ni}$, have been investigated by Bergman, ${ }^{\mathbf{1 4}}$ Maiti, ${ }^{\mathbf{1 5}}$ and Tobisu. ${ }^{16} \mathrm{Ru}^{17}$ or $\mathrm{Mn}^{18}$ also was used to catalyze indirect Friedländer synthesis to obtain 2-arylated quinolines that involved oxidative cyclization of 2-aminobenzyl alcohol with either ketones or alcohols. Although these processes were highly efficient and significance, none of these procedures could directly provide the final products with a low content of the heavy metal impurities which are strict restrictions in drugs and pharmaceuticals. ${ }^{19}$ Thus, an alternative, general, solventfree, and environmentally sustainable procedure is urgently required for the quick synthesis of 2-arylated quinolines.

Recently, as our continuous study on the $\mathrm{C}\left(\mathrm{sp}^{3}\right)-\mathrm{H}$ activation of 2-methylquinolines, which provided a facile synthetic approach to access substituted pyrrolo[1,2-a]quinolones (Scheme 1), ${ }^{20}$ we had found that the methyl of 2-

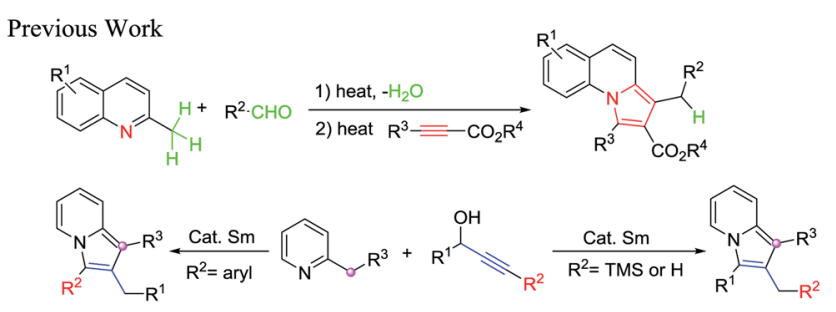

This Work

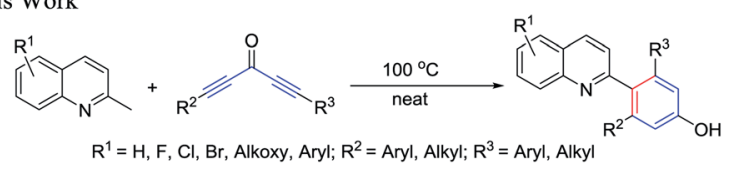

Scheme $1 \mathrm{C}-\mathrm{H}$ bond activation of 2-methylquinolines and 2methylpyridine. 
Table 1 Optimization of reaction conditions ${ }^{a}$

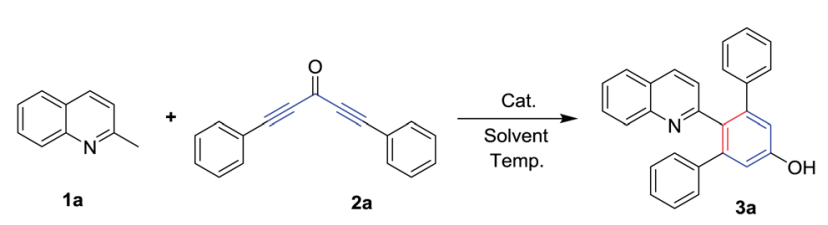

\begin{tabular}{lllll}
\hline Entry & Cat. & Solvent & Temp. $\left({ }^{\circ} \mathrm{C}\right)$ & Yield $^{b}(\%)$ \\
\hline 1 & - & PhCl & 120 & 65 \\
2 & $\mathrm{Sm}(\mathrm{OTf})_{3}$ & $\mathrm{PhCl}$ & 120 & 55 \\
$3^{c}$ & $\mathrm{Sm}^{c}(\mathrm{OTf})_{3}$ & $\mathrm{PhCl}$ & 120 & 0 \\
4 & $\mathrm{Cs}_{2} \mathrm{CO}_{3}$ & $\mathrm{PhCl}$ & 120 & 0 \\
5 & $\mathrm{Et}_{3} \mathrm{~N}$ & $\mathrm{PhCl}$ & 120 & 0 \\
6 & $\mathrm{AcOH}$ & $\mathrm{PhCl}$ & 120 & 0 \\
7 & - & Toluene & 120 & 35 \\
8 & - & DMF & 120 & 63 \\
9 & - & DMSO & 120 & 45 \\
10 & - & $1,4-$ Dioxane & 120 & Trace \\
$11^{d}$ & - & - & 120 & 73 \\
$12^{d}$ & - & - & 110 & 75 \\
$\mathbf{1 3}^{d}$ & - & - & $\mathbf{1 0 0}$ & $\mathbf{8 5}$ \\
$14^{d}$ & - & - & 90 & 60 \\
$15^{d, e}$ & - & - & 100 & 86
\end{tabular}

${ }^{a}$ Reactions conditions: $1 \mathrm{a}(0.6 \mathrm{mmol}), 2 \mathrm{a}(0.5 \mathrm{mmol})$, catalyst $(10 \mathrm{~mol} \%$ to $2 \mathrm{a}$ ), solvent ( $1 \mathrm{~mL}$ ), sealed tube, $10 \mathrm{~h} .{ }^{b}$ Isolated yield of pure product based on 2 a. ${ }^{c} \mathrm{Cs}_{2} \mathrm{CO}_{3}$ as base was added to the reaction. ${ }^{d} \mathbf{1 a}(1.5$ mmol), $2 \mathrm{a}(0.5 \mathrm{mmol})$, sealed tube, $10 \mathrm{~h} .{ }^{e}$ Reaction time was $15 \mathrm{~h}$.

methylquinolines has very high reactivity. Based on this, herein we reported the catalyst-free and solvent-free $[5+1]$ annulation of 2-methylquinolines and diynones to access 4-(quinolin-2-yl)phenols. To the best of our knowledge, there were none of the group that reported direct construction of six-member aromatic-ring at the methyl of 2-methylquinolines with diynones to give 4-(quinolin-2-yl)-phenols. The present novel construction protocol for 4-(quinolin-2-yl)-phenols had several significant advantages: (1) this chemistry provided a novel and simple strategy for the synthesis of highly valuable 4-(quinolin2-yl)-phenols under very simple conditions; (2) according to the atom economy concept, this protocol was carried out under catalyst-free and solvent-free conditions, without the addition of any acid, base, or other reagents, which provided the final products without heavy metal impurities and improved its potential utility; (3) the method featured high functional group tolerance, high yields, and broad substrate scopes. Particularly, this route could directly introduce two different substituent groups on the newly formed of six-member aromatic-ring (see Table 2).

To examine the feasibility of our proposed protocol, 2methylquinoline (1a) and 1,5-diphenylpenta-1,4-diyn-3-one (2a) were chosen as the model substrates and diverse reaction conditions were screened as shown in Table 1 . Initially, treatment of $1 \mathrm{a}(0.6 \mathrm{mmol})$ with $2 \mathrm{a}(0.5 \mathrm{mmol})$ in chlorobenzene $(\mathrm{PhCl})$ at $120{ }^{\circ} \mathrm{C}$ for 10 hours led to the arylation product $2^{\prime}$ (quinolin-2-yl)-[1,1': $3^{\prime}, 1^{\prime \prime}$-terphenyl]-5'-ol (3a) in $65 \%$ yield (Table 1, entry 1). The structure of $3 \mathbf{a}$ was confirmed by its ${ }^{1} \mathrm{H}$

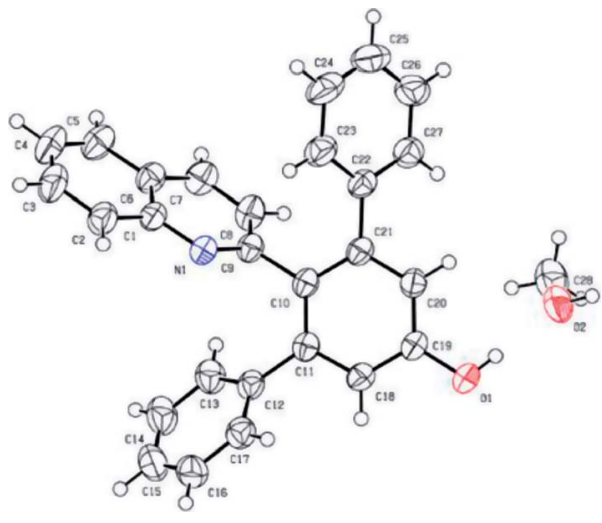

Fig. 1 X-ray crystal structure of 3a (CCDC 1534893†).

and ${ }^{13} \mathrm{C}$ NMR spectra, mass spectra, and single-crystal X-ray diffraction analysis (Fig. 1). ${ }^{21}$ To improve the efficiency, we used $\mathrm{Sm}(\mathrm{OTf})_{3}$ as catalyst, but the result provided $3 \mathrm{a}$ in less than $60 \%$ (Table 1, entry 2). And then, when we used base $\left(\mathrm{Cs}_{2} \mathrm{CO}_{3}\right.$, $\left.\mathrm{Et}_{3} \mathrm{~N}\right)$ or acid $(\mathrm{AcOH})$ as additives, no desired products was isolated (Table 1, entries 4-6) because of 2a degradation in the presence of acid or base. Subsequently, we used other solvents such as toluene, DMF, DMSO, and 1,4-dioxane in place of $\mathrm{PhCl}$ and these reactions were completed in the absence of additives, providing the yields of $3 \mathrm{a}$ in less than $65 \%$ (Table 1, entries 710). Gratifyingly, when the reaction was carried out in the

Table 2 Synthesis of 4-(quinolin-2-yl)phenol derivatives ${ }^{a, b, c}$

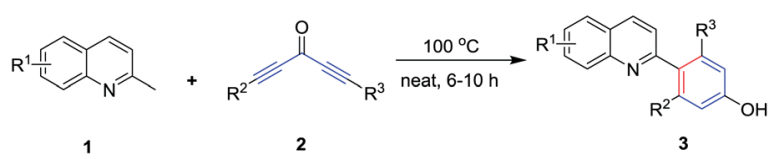

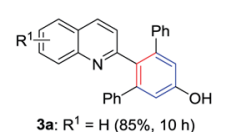

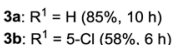
3b: $R^{1}=5-C l(58 \%, 6 h)$
3c: $R^{1}=6-F(55 \%, 6 h)$

3d: $R^{1}=6-B r(77 \%, 10 h)$

3e: $R^{1}=7-\mathrm{Cl}(60 \%, 7 \mathrm{~h})$

3f: $R^{1}=6$-EtO $(58 \%, 6 \mathrm{~h})$

3g: $\mathrm{R}^{1}=6-\mathrm{Cl}-7-\mathrm{Cl}(73 \%, 10 \mathrm{~h})$

(1)

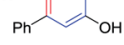

3k: $68 \%, 9 \mathrm{~h}$

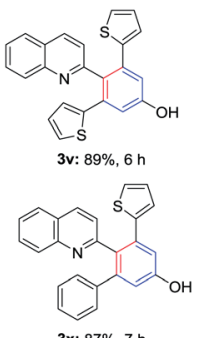

$3 x: 87 \%, 7 \mathrm{~h}$

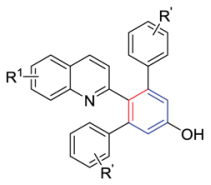

3h: $R^{1}=6-B r, R^{\prime}=4-M e(70 \%, 10 h)$ 3i: $R^{1}=7-F, R^{\prime}=3-M e(62 \%, 7 h)$

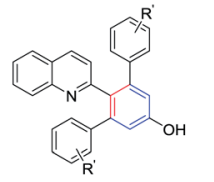

3I: $\mathrm{R}^{\prime}=2-\mathrm{Cl}(82 \%, 8 \mathrm{~h})$ $3 \mathrm{~m}: \mathrm{R}^{\prime}=3-\mathrm{Me}(75 \%, 9 \mathrm{~h})$ 3n: $R^{\prime}=3-M e O(65 \%, 10 h)$ 3o: $R^{\prime}=4-M e(73 \%, 9 h)$
3p: $R^{\prime}=4-E t(70 \%, 9 h)$ $3 \mathrm{p}: \mathrm{R}^{\prime}=4-E t(70 \%, 9 \mathrm{~h})$
$3 \mathrm{q}: \mathrm{R}^{\prime}=4-\mathrm{F}(79 \%, 7 \mathrm{~h})$

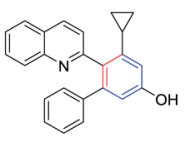

3y: $67 \%, 9 \mathrm{~h}$

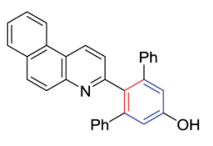

3j: $82 \%, 10 \mathrm{~h}$

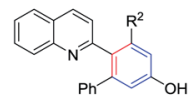

3r: $\mathrm{R}^{2}=4-\mathrm{FC}_{6} \mathrm{H}_{4}(76 \%, 8 \mathrm{~h})$ 3s: $\mathrm{R}^{2}=4-\mathrm{ClC}_{6} \mathrm{H}_{4}(74 \%, 8 \mathrm{~h})$ 3t: $\mathrm{R}^{2}=3-\mathrm{Me}^{-5}-\mathrm{MeC}_{6} \mathrm{H}_{3}(68 \%, 9 \mathrm{~h})$ 3u: $\mathrm{R}^{2}=n-\mathrm{C}_{3} \mathrm{H}_{7}(70 \%, 10 \mathrm{~h})$
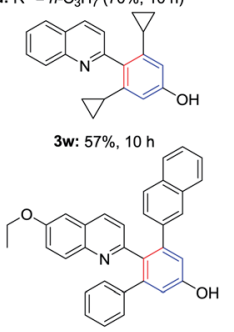

3z: $63 \%, 8 \mathrm{~h}$
${ }^{a}$ Yield of the isolated product, calculated from $2 .{ }^{b}$ The reaction completed under solvent-free (see ESI). ${ }^{c} \mathbf{3 d}, \mathbf{3 g}, \mathbf{3 h}, \mathbf{3 \mathbf { j }}$ completed in PhCl (see ESI). 
absence of solvent, the yield of corresponding product 3a was increased to $73 \%$ (Table 1, entry 11 ). Subsequently, we carefully adjusted the reaction temperature (Table 1, entries 12-14) and the desired product 3a was obtained in the best yield (85\%) when the reaction was performed at $100{ }^{\circ} \mathrm{C}$. The reaction time extended to 15 hours, but the yield of $3 \mathbf{a}$ was not increased (Table 1, entry 15).

With the optimized conditions in hand, a series of diynones and 2-methylquinolines were subjected to the reaction to investigate the scope and the results were shown in Table 2. The 2-methylquinoline ring has been substituted with electron-rich or electron-deficient groups $\mathrm{R}^{1}$ whereas $\mathrm{R}^{2}, \mathrm{R}^{3}$ in the diynones included alkyl and aryl moieties. All reactions proceeded smoothly to afford the corresponding 4-(quinolin-2-yl)phenols/ 4-(pyridin-2-yl)phenols in moderate to high yields (55-89\%). Desired products $\mathbf{3 b} \mathbf{b} \mathbf{3}$ were obtained in moderate to good yields $(55-77 \%)$ with an electron-rich group (-EtO) or electrondeficient substituent $(-\mathrm{F},-\mathrm{Cl},-\mathrm{Br})$ at $\mathrm{C}-5, \mathrm{C}-6$, or $\mathrm{C}-7$ of $2-$ methylquinolines. The reaction of 6,7-dichloro-2methylquinoline and diynones provided the corresponding product $3 \mathrm{~g}$ in $73 \%$ yield with the $\mathrm{PhCl}$ as solvent. Symmetric diynones bearing electron-donating substituents such as Me, $\mathrm{MeO}$, and Et or electron-withdrawing groups such as $\mathrm{F}$ and $\mathrm{Cl}$ on the benzene ring were found to be good substrates for this reaction and provided the desired products (31-3q) in moderate to high yields, which showed that the position of the substituents on the benzene ring did not affect the transformation significantly. In addition, the diynones reacted with 2-methylquinoline which has an electron-deficient substituent at C-6 or C-7, furnishing the corresponding 4-(quinolin-2-yl)-phenols products in good yields $(\mathbf{3 h}, \mathbf{3} \mathbf{i})$. It was found that the reaction of the 3-methylbenzo[f]quinoline and 2,6-dimethylpyridine also proceeded smoothly and afforded the desired product $\mathbf{3 j}$ and $\mathbf{3 k}$ in $82 \%$ and $68 \%$ yields, respectively. Unfortunately, the reaction of 2-methylpyridine and 1,5-diphenylpenta-1,4-diyn-3-one (2a) under the standard conditions only give a trace amount of the desired product. Then, we investigated the reaction with heterocycle substituted diynones, and found the thiophene substrates furnishing the desired product in higher yield (3v). Subsequently, other asymmetrical diynones which have two different substituents were also tested for the present reaction and the corresponding products were isolated in good to excellent yields $(\mathbf{3 r}-\mathbf{3 u}, \mathbf{3} \mathbf{x}-\mathbf{3 z})$. We found that strained cyclopropyl was tolerated for this transformation and provided the corresponding products $\mathbf{3 w}$ and $\mathbf{3 y}$ in moderate yields.

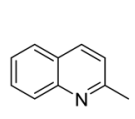

1a

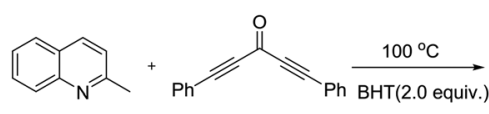

$2 a$

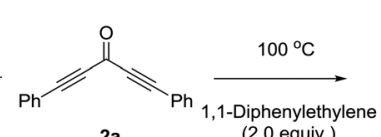

2a

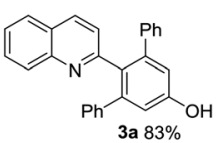

(1)

Scheme 2 Control experiments.

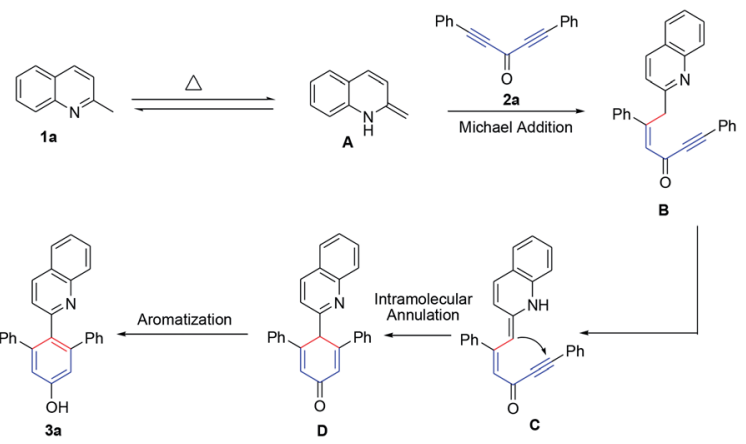

Scheme 3 Plausible mechanism.

To support the proposed reaction pathway, additional control experiments were carried out and the results were presented in Scheme 2. It was observed that the presence of 2 equiv. of 1,1diphenylethylene or BHT (2,6-di-tert-butyl-4-methylphenol) didn't suppress the synthesis of 3a. These results suggested that a radical mechanism wasn't likely involved.

A possible mechanism is proposed in Scheme 3. At first, the enamine intermediate A was formed from 1a via tautomerization, ${ }^{22}$ followed by, Michael addition to diynones, giving the intermediate $\mathbf{B}$. And then, the enamine intermediate $\mathbf{C}$ was generated from $\mathbf{B}$ via the requisite disruption of aromaticity. Subsequently, intermediate $\mathbf{C}$ was transformed into intermediate $\mathbf{D}$ by intramolecular annulation reaction and the intermediate $\mathbf{D}$ was rapidly aromatized to form the stable product $\mathbf{3 a}$.

In summary, we have developed a rapid, simple, efficient, catalyst-free, and solvent-free reaction to access 4-(quinolin-2yl)-phenols through a $[5+1]$ annulation directly from 2-methylquinolines and diynones. The synthetic process was atomeconomic, applicable to wide range of substrates, and has functional group tolerance, and these features would render this method attractive for academic and industrial use.

\section{Conflicts of interest}

There are no conflicts to declare.

\section{Acknowledgements}

We would like to thank the National Natural Science Foundation of China (41465009 and 21362002), Guangxi Natural Science Foundation of China (2017GXNSFDA198043, 2016GXNSFEA380001, 2016GXNSFGA380005 and AA17204058), Ministry of Education of China (IRT_16R15) and BAGUI Scholar Program of Guangxi Province of China (2016A13).

\section{Notes and references}

1 (a) Y. Hitora, K. Takada, Y. Ise, S. Okada and S. Matsunaga, J. Nat. Prod., 2016, 79, 2973; (b) H. Fan, J.-G. Peng, M. T. Hamann and J.-F. Hu, Chem. Rev., 2008, 108, 264; (c) B. Boucherle, R. Haudecoeur, E. F. Queiroz, M. de Waard, J.-L. Wolfender, R. J. Robins and A. Boumendjel, Nat. Prod. Rep., 2016, 33, 1034; (d) H.-T. Tang, K. Xiong, R.-H. Li, 
Z.-C. Ding and Z.-P. Zhan, Org. Lett., 2015, 17, 326; (e) J.-J. Wen, H.-T. Tang, K. Xiong, Z.-C. Ding and Z.-P. Zhan, Org. Lett., 2014, 16, 5940; (f) X. Tang, Z. Zhu, C. Qi, W. Wu and H. Jiang, Org. Lett., 2016, 18, 180; $(g)$ P. Li, X. Zhang and X. Fan, J. Org. Chem., 2015, 80, 7508; (h) S.-S. Zhang, J.-Q. Wu, X. Liu and H. Wang, ACS Catal., 2015, 5, 210.

2 (a) W. R. Gutekunst, R. Gianatassio and P. S. Baran, Angew. Chem., Int. Ed., 2012, 124, 7625; (b) P. B. Arockiam, C. Bruneau and P. H. Dixneuf, Chem. Rev., 2012, 112, 5879; (c) S. H. Cho, J. Y. Kim, J. Kwak and S. Chang, Chem. Soc. Rev., 2011, 40, 5068; (d) X. Chen, K. M. Engle, D.-H. Wang and J.-Q. Yu, Angew. Chem., Int. Ed., 2009, 121, 5196.

3 R. W. Friesen, C. Brideau, C. C. Chan, S. Charleson, D. Deschênes, D. Dubé, D. Ethier, R. Fortin, J. Y. Gauthier, Y. Girard, R. Gordon, G. M. Greig, D. Riendeau, C. Savoie, Z. Wang, E. Wong, D. Visco, L. J. Xu and R. N. Young, Bioorganic Med. Chem. Lett., 1998, 8, 2777.

4 J. Quirk, M. Thornton and P. Kirkpatrick, Nature, 2003, 2, 769.

5 R. Capdeville, E. Buchdunger, J. Zimmermann and A. Matter, Nature, 2002, 1, 493.

6 (a) G. Chelucci, G. Orru and G. A. Pinna, Tetrahedron, 2003, 59, 9471; (b) N. W. Alcock, J. M. Brown and D. I. Hulmes, Tetrahedron: Asymmetry, 1993, 4, 743; (c) J. S. Carey, D. Laffan, C. Thomson and M. T. Williams, Org. Biomol. Chem., 2006, 4, 2337; (d) V. Bonnet, F. Mongin, F. Trécourt, G. Breton, F. Marsais, P. Knochel and G. Quéquiner, Synlett, 2002, 1008.

7 (a) N. Kaila, K. Janz, S. DeBernardo, P. W. Bedard, R. T. Camphausen, S. Tam, D. H. H. Tsao, J. C. Keith Jr, C. Nickerson-Nutter, A. Shilling, R. Young-Sciame and Q. Wang, J. Med. Chem., 2007, 50, 21; (b) A. Zarghi, R. Ghodsi, E. Azizi, B. Daraie, M. Hedayati and O. G. Dadrass, Bioorg. Med. Chem., 2009, 17, 5312; (c) R. Ghodsi, A. Zarghi, B. Daraei and M. Hedayati, Bioorg. Med. Chem., 2010, 18, 1029.

8 M. J. Iglesias, A. Prieto and M. C. Nicasio, Org. Lett., 2012, 17, 4318.

9 (a) V. Arumugam, W. Kaminsky and D. Nallasamy, RSC Adv., 2015, 5, 77948; (b) D.-H. Lee, J. Young and M.-J. Jin, Green Chem., 2010, 12, 2024; (c) J.-F. Yang, S.-J. Liu, J.-F. Zheng and J.-R. Zhou, Eur. J. Org. Chem., 2012, 6248; (d) Y.-J. Zou, G.-Z. Yue, J.-W. Xu and J.-R. Zhou, Eur. J. Org. Chem., 2014, 5901.

10 (a) D. Haas, J. M. Hammann, F. H. Lutter and P. Knochel, Angew. Chem., Int. Ed., 2016, 55, 3809; (b) Z.-L. Liu, N.-N. Dong, M.-Z. Xu, Z.-M. Sun and T. Tu, J. Org. Chem., 2013, 78, 7436.
11 (a) A. Lützen and M. Hapke, Eur. J. Org. Chem., 2002, 2292; (b) D. C. Blakemore and L. A. Marples, Tetrahedron Lett., 2011, $52,4192$.

12 (a) L.-H. Kong, S.-J. Yu, X.-K. Zhou and X.-W. Li, Org. Lett., 2016, 18, 588; (b) D.-B. Zhao, W.-H. Wang, F. Yang, J.-B. Lan, L. Yang, G. Gao and J.-S. You, Angew. Chem., Int. Ed., 2009, 48, 3296; (c) L.-C. Campeau, D. R. Stuart, J.-P. Leclerc, M. Bertrand-Laperle, E. Villemure, H.-Y. Sun, S. Lasserre, N. Guimond, M. Lecavallier and K. Fagnou, J. Am. Chem. Soc., 2009, 131, 3291; (d) Q.-Q. Lu, S. VásquezCéspedes, T. Gensch and F. Glorius, ACS Catal., 2016, 6, 2352; (e) Q.-Q. Yan, Z.-K. Chen, Z.-X. Liu and Y.-H. Zhang, Org. Chem. Front., 2016, 3, 678.

13 (a) S.-M. Li, J. Huang, G.-J. Chen and F.-S. Han, Chem. Commun., 2011, 47, 12840; (b) C. K. Haley, C. D. Gilmore and B. M. Stoltz, Tetrahedron, 2013, 69, 5732; (c) K. Muto, T. Hatakeyama, K. Itami and J. Yamaguchi, Org. Lett., 2016, 18, 5106.

14 (a) A. M. Bergman, R. G. Bergman and J. A. Ellman, J. Org. Chem., 2010, 75, 7863; (b) A. M. Bergman, J. C. Lewis, R. G. Bergman and J. A. Ellman, J. Am. Chem. Soc., 2008, 130, 14926.

15 A. Deb, S. Manna, A. Maji, U. Dutta and D. Maiti, Eur. J. Org. Chem., 2013, 5251.

16 (a) I. Hyodo, M. Tobisu and N. Chatani, Chem.-Asian J., 2012, 7, 1357; (b) M. Tobisu, I. Hyodo and N. Chatani, J. Am. Chem. Soc., 2009, 131, 12070.

17 (a) H. V. Mierde, P. V. D. Voort, D. D. Vos and F. Verpoort, Eur. J. Org. Chem., 2008, 1625; (b) R. Martínez, D. J. Ramón and M. Yus, Eur. J. Org. Chem., 2007, 1599; (c) D. Srimani, Y. Ben-David and D. Milstein, Chem. Commun., 2013, 49, 6632; (d) C. S. Cho, B. T. Kim, T.-J. Kim and S. C. Shim, Chem. Commun., 2001, 2576; (e) B. Pan, B. Liu, E. Yue, Q.-B. Liu, X.-Z. Yang, Z. Wang and W.-H. Sun, ACS Catal., 2016, 6, 1247.

18 M. Mastalir, M. Glatz, E. Pittenauer, G. Allmaier and K. Kirchner, J. Am. Chem. Soc., 2016, 138, 15543.

19 (a) V. Balaram, TrAC, Trends Anal. Chem., 2016, 80, 83; (b) C. E. Garrett and K. Prasad, Adv. Synth. Catal., 2004, 346, 889. 20 (a) F.-S. Wu, H.-Y. Zhao, Y.-L. Xu, K. Hu, Y.-M. Pan and X.-L. Ma, J. Org. Chem., 2017, 82, 4289; (b) X. Wang, S.-Y. Li, Y.-M. Pan, H.-S. Wang, H. Liang and Z.-F. Chen, Org. Lett., 2014, 16, 580.

21 CCDC 1534893 (3a) contains the supplementary crystallographic data for this paper. $\dagger$

22 L.-B. Xu, Z.-Z. Shao, L. Wang, H.-L. Zhao and J. Xiao, Tetrahedron Lett., 2014, 55, 6856. 